\title{
Gestão de Projetos e Sustentabilidade na Construção Civil
}

\author{
Project Management and Sustainability in Civil Construction
}

Resumo: Os projetos desenvolvidos em empresas e organizações têm impactos no presente e em um futuro mais distante. Assim sendo, o objetivo do trabalho é o entendimento da aplicação da sustentabilidade na Construção civil utilizando a gestão de projetos como um meio facilitador de todo o processo. A metodologia mescla técnicas de análise de conteúdo e pesquisas quantitativas. As temáticas remetem a inovação tecnológica, processos de gestão, com ênfase para publicações na área da construção civil. Além da questão ética e ambiental, a sustentabilidade é uma demanda por parte dos clientes finais que vem crescendo cada vez mais. Boa parte da sociedade vem mudando seus hábitos prejudiciais ao meio ambiente e com isso surge a necessidade de construções cada vez mais sustentáveis. O resultado dessa pesquisa trará informações pertinentes de modelos de gestão e soluções sustentáveis para serem aplicadas em um novo projeto.

Palavras-chave: Gestão de projetos. Sustentabilidade. Construção civil.

Abstract: Projects developed in companies and organizations have an impact on the present and the more distant future. Therefore, the objective of the work is to understand the application of sustainability in Civil Construction using project management as a means of facilitating the entire process. The methodology mixes content analysis techniques and quantitative research. The themes refer to technological innovation, management processes, with emphasis on publications in the area of civil construction. In addition to the ethical and environmental issue, sustainability is a demand on the part of end customers that has been growing more and more. A good part of society has been changing its harmful habits to the environment and with that the need for more and more sustainable buildings arises. The result of this research will bring pertinent information on management models and sustainable solutions to be applied in a new Project.

Keywords: Project management. Sustainability. Construction. 


\title{
1 Introdução
}

A pauta da sustentabilidade, há tempos conhecida como uma tentativa de harmonizar o pilar financeiro tradicional com o pensamento emergente sobre o pilar ambiental, está agora se revelando muito mais complicada do que aquilo que alguns executivos entusiastas haviam imaginado no início. "Cada vez mais, estamos pensando em termos de "três pilares", com enfoque na prosperidade econômica, na qualidade ambiental e no elemento ao qual as empresas tendem a fazer vistas grossas, a justiça social." (Elkington, 2012, p. 226).

Um crescente número de empresas que geram relatórios está sinalizando o reconhecimento da necessidade de dar atenção à linha dos três pilares. A Shell disse em seu primeiro relatório, publicado em 1996:

\begin{abstract}
A Shell do Reino Unido reconhece que pode haver um verdadeiro interesse na forma como ela conduz seu negócio. Ela tentou ser aberta em relação a suas operações, princípios e padrões. No entanto, reconhece que em um mundo que esteja sofrendo mudanças, onde as pessoas estão cada mais interessadas no equilíbrio entre o social, o econômico e o ambiental, ela deve fazer muito mais para engajar o público nas difíceis escolhas ambientais. (SHELL, 1996, "não paginado").
\end{abstract}

De forma simples, esse é o novo paradigma dos negócios do século 21 . O desenvolvimento sustentável é proposto pelos governos e líderes corporativos como solução para uma grande gama de problemas que agora estão começando a fazer parte da pauta internacional. O primeiro relatório das Nações Unidas, Global Environmental Outlook, publicado em 1996, mencionou que o mundo ainda não possui "o senso de urgência necessário" que é preciso para se afastar do "precipício ambiental.” (Elkington, 2012, p. 52). "O princípio de sustentabilidade surge no contexto da globalização como marca de um limite e o sinal que reorienta o processo civilizatório da humanidade. A crise ambiental veio questionar a racionalidade e os paradigmas teóricos que impulsionaram e legitimaram o crescimento econômico, negando a natureza.” (Leff, 2012, p. 15).

Temos visto que o desenvolvimento sustentável, como tem sido amplamente chamada a busca pela sustentabilidade, apresenta um antagonismo no seu próprio entendimento semântico. "Uma vez que a palavra desenvolvimento implica a utilização dos recursos da natureza para o benefício do ser humano, a palavra sustentável conota, ao mesmo tempo, a preservação dessa mesma natureza.” (Malvezzi, 2013, p. 64). Dessa forma, observa-se que os conceitos sustentabilidade e desenvolvimento sustentável não estão necessariamente alinhados entre as várias publicações. Para fins deste trabalho, adota-se o termo 
sustentabilidade e desenvolvimento sustentável, por vezes sem uma clara definição que os distinga. O entendimento desses termos à luz da gestão de projetos precisa amadurecer para ter uma definição clara dos termos.

O presente trabalho tem como objetivo realizar uma revisão sistemática de literatura, buscando artigos e livros que tenham abrangência em ambos os temas, tanto gestão de projetos quanto sustentabilidade na construção civil. Busca-se identificar os principais assuntos apresentados no âmbito dessas temáticas, identificando tendências e déficits, bem como os principais autores e obras.

O artigo está estruturado em quatro seções: a seção 2 descreve a metodologia de seleção da amostra de artigos e livros a serem analisados. Na seção 3 são apresentados os resultados e a discussão da pesquisa, seguidos das conclusões, na seção 4 .

\section{Desenvolvimento: métodos}

A abordagem metodológica adotada nesta revisão sistemática da literatura, mescla técnicas de análise de conteúdo e pesquisas quantitativas. A técnica de análise de conteúdo (Bardin, 2011) foi utilizada na codificação e análise das principais temáticas da pesquisa onde prevê três fases fundamentais, conforme o esquema apresentado na Figura 1: pré-análise, exploração do material e tratamento dos resultados $-a$ inferência e a interpretação.

Figura 1: Três fases da Análise de Conteúdo

\section{ANÁLISE DE CONTEÚDO}

Pré-análise

Fonte: Adaptado de Bardin (2011)
Tratamento dos resultados: inferência e interpretação

A análise de dados foi feita em duas etapas. Na primeira etapa, os dados primários da amostra foram tratados, buscando-se ter uma visão quantitativa das publicações, tratando-se os dados e agrupando-os por 
Marina Silva Paravidino de Abreu

ano de publicação, revista de publicação, número de citações, entre outros. Dado que o próprio banco de dados fornece as informações necessárias para tais análises de forma razoável, a sua execução foi possível por meio de um tratamento em planilhas eletrônicas.

A segunda e última etapa de tratamento dos dados está baseada na análise de conteúdo dos artigos da amostra. Assim por meio da leitura dos resumos e, eventualmente, do artigo na íntegra, foi feita a classificação entre econômico, ambiental e social conforme o conceito do triple bottom line de Elkington (2012). É fato que esses assuntos se correlacionam de forma significativa, porém, houve um empenho em identificar o ponto predominante de cada artigo onde foi feita uma seleção de 2 artigos que tinham em comum um dos pilares da sustentabilidade. Para aprimorar a análise de conteúdo, foram identificados nesses 2 artigos da amostra que têm no título, no resumo ou como palavra-chave os termos sustentabilidade, gestão e construção.

\subsection{Amostra e procedimento de busca}

A amostra inicial foi obtida a partir de buscas na base Scientific Eleetronic Library Online (SciELO). Isso porque sua abrangência é bastante significativa, uma vez que nela é possível localizar informações de vários periódicos indexados. Além disso, essa base é capaz de fornecer a amostra inicial como também as suas referências, permitindo uma análise mais aprofundada das informações extraídas do banco de dados.

Empregou-se o termo sustentabilidade nas análises. Essa primeira etapa resultou em um grande número de artigos, totalizando 2.456 títulos. Restringindo essas publicações com um novo filtro, project management, o banco de dados identificou 2.265 textos, contemplando os diversos tipos de publicação. Assim, a amostra utilizada pela presente pesquisa foi obtida, finalmente, selecionando-se somente as publicações do tipo artigo. Dessa forma o número de títulos contidos na amostra utilizada para análise chegou a 46 artigos.

\section{Apresentação e discussão dos resultados}

A seção a seguir tem como objetivo discutir os resultados das análises conduzidas a partir da amostra obtida, para que seja possível ter-se uma visão geral das publicações relativas à gestão de projetos e sustentabilidade. 


\subsection{Análise inicial}

Observando-se o número de artigos publicados que tratam do tema gestão de projetos associado de alguma forma a sustentabilidade, verifica-se a presença de títulos desde 1991. Vale ressaltar que há um evidente crescimento desde 2005, com destaque para 2007 e 2015 (Figura 2).

Além disso, observando-se os dados obtidos é possível ver que os trabalhos da amostra estudada apresentam dispersão bastante considerável, podendo-se verificar isso principalmente na evolução das publicações ao longo do ano e na análise do número de artigos por revista conforme mostrado pelas figuras 2 e 3. Isso porque as duas revistas que mais estiveram presentes na amostra, ambas da área de Gestão (Gestão e Produção e Production), possuem um número razoável de artigos associados, sendo a primeira revista com 121 e a segunda com 44.

Figura 2. Evolução das publicações ao longo do tempo. Nota: "Estimado a partir das publicações até mar./2020.

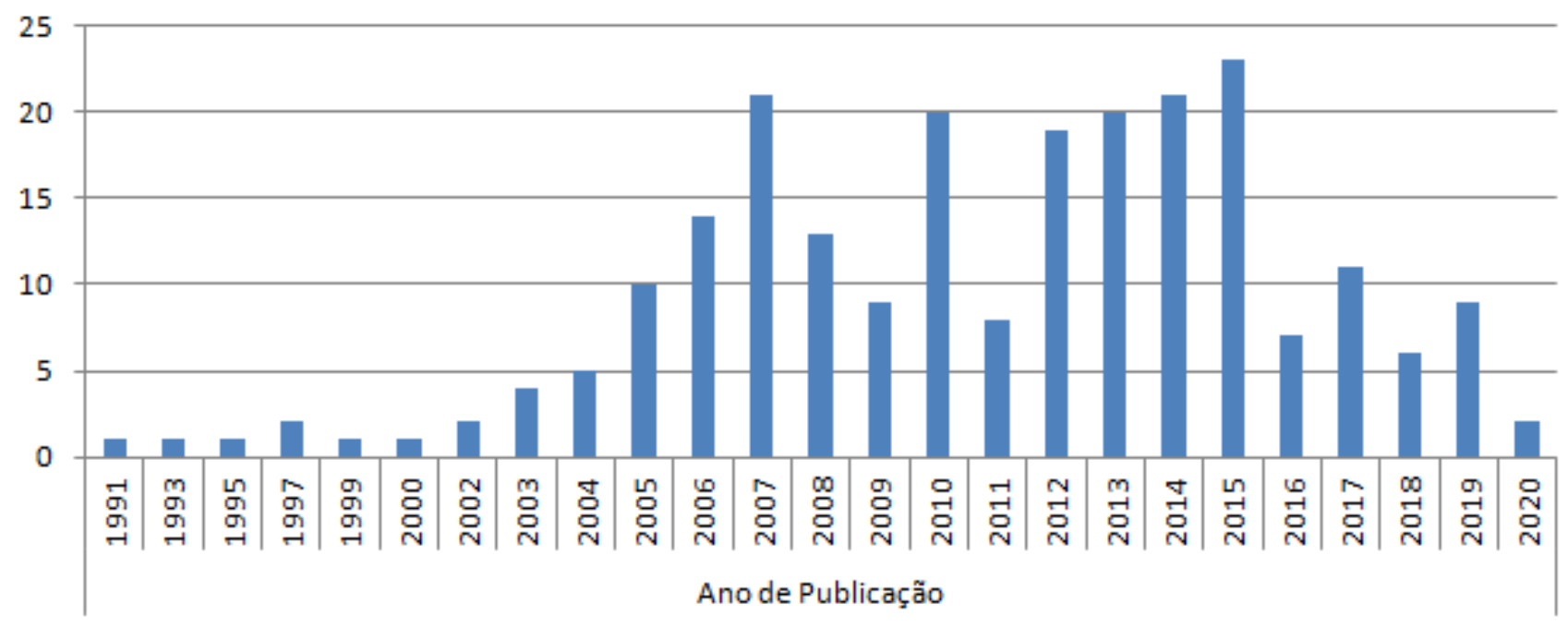

Fonte: Elaboração própria (2020). 
Figura 3. Gráfico de relevância das revistas da amostra.

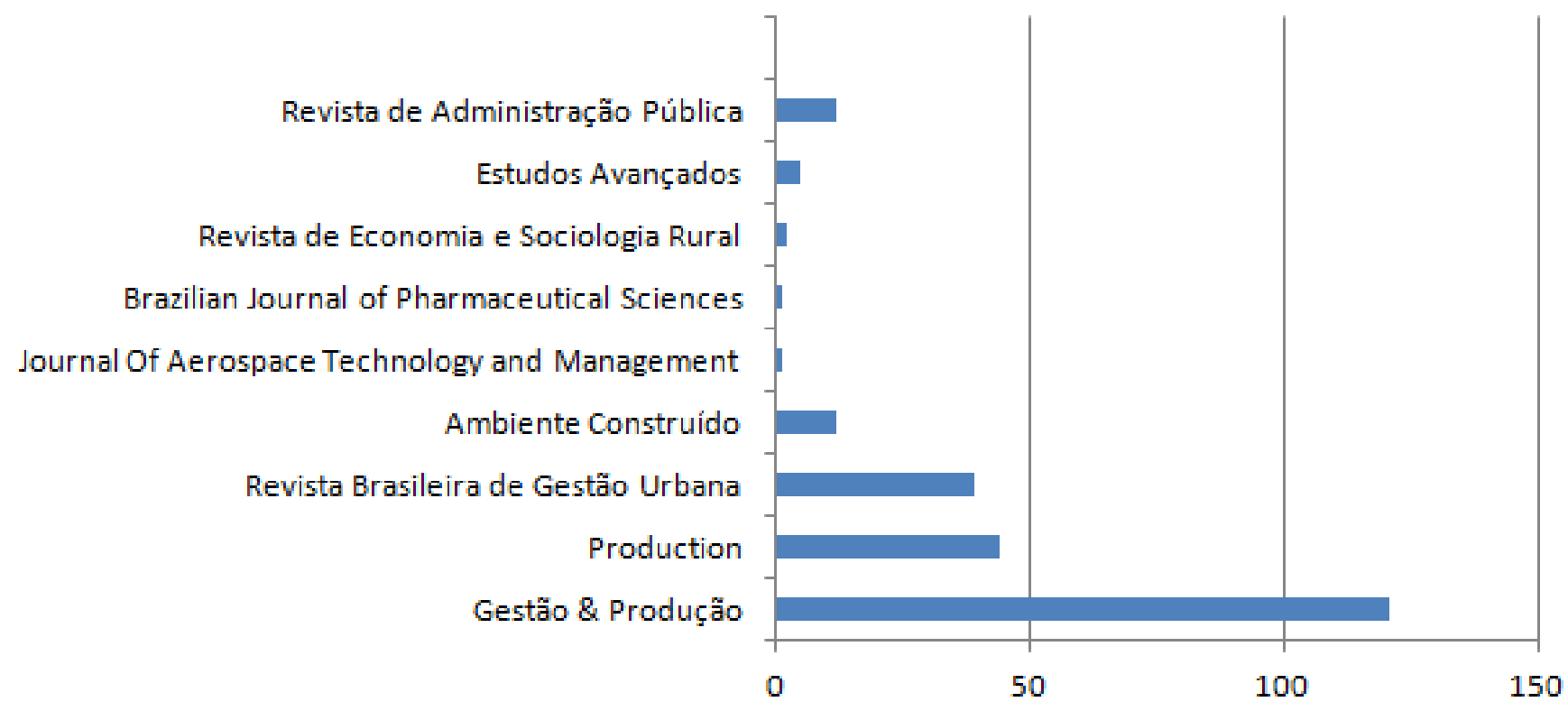

Fonte: Elaboração própria (2020).

Considerando os artigos da base de dados SciELO, as referências da amostra analisada que foram mais citadas são mostradas na Tabela 1. Os trabalhos tratam de Gerenciamento de Projetos e também da parte ambiental. Observa-se pelo critério de citação que destacam-se os artigos de Mora-Ortiz (2015), seguidos pelos de Zart ambos focam o conceito de sustentabilidade, priorizando a gestão na perspectiva econômica.

Assim, a partir dessas análises iniciais é possível chegar à conclusão parcial de que as pesquisas na interface entre gestão de projetos e sustentabilidade ainda estão bastante dispersas, tanto no que concerne aos veículos de publicação como em relação aos autores e obras de referência. Vale destacar que os principais trabalhos, considerando-se os critérios de citação e número de artigos publicados, não debateram especificamente a inserção de práticas (processos, ferramentas e métodos) de sustentabilidade na gestão de projetos. 
Marina Silva Paravidino de Abreu

Estácio Universidade Estácio de Sá, Campos dos Goytacazes, RJ, Brasil

marina.paravidino@live.com

ARTIGO

Tabela 1. Os trabalhos mais citados.

\begin{tabular}{|c|c|c|}
\hline Autores & $\begin{array}{l}\text { Ano de } \\
\text { Publicação }\end{array}$ & Principal abordagem \\
\hline Mora-Ortiz et al. & 2015 & $\begin{array}{l}\text { Projetos Ambientais Escolares. Ferramentas de } \\
\text { Gestão ambiental. }\end{array}$ \\
\hline Zartha et al. & 2012 & $\begin{array}{l}\text { Implementação da metodologia de gestão } \\
\text { tecnológica para projetos "MGT" em empresas do } \\
\text { setor agro industrial. }\end{array}$ \\
\hline Araque Solano et al. & 2014 & $\begin{array}{l}\text { Modelo de Gestão de Projetos imobiliários de } \\
\text { renovação urbana. }\end{array}$ \\
\hline García et al. & 2012 & $\begin{array}{l}\text { Considerações de ética ambiental na gestão } \\
\text { integral dos recursos hídricos da bacia do rio } \\
\text { Quindio. }\end{array}$ \\
\hline Montes et al. & 2015 & $\begin{array}{l}\text { Gerenciamento de projetos em cooperação para o } \\
\text { desenvolvimento. Organizações não } \\
\text { governamentais. }\end{array}$ \\
\hline Garrido et al. & 2013 & $\begin{array}{l}\text { Programação reativa em gerenciamento de } \\
\text { projetos: abordagem conceitual e aplicações } \\
\text { práticas. }\end{array}$ \\
\hline
\end{tabular}

Fonte: Elaboração própria (2020).

\subsection{Os pilares da sustentabilidade}

Conforme discutido inicialmente, a sustentabilidade considera três pilares: sociedade, economia e meio ambiente (Elkington, 2012). Os artigos da amostra foram classificados em uma das quatro perspectivas, tendo em vista a ênfase em cada um dos pilares da sustentabilidade ou no próprio triple bottom line, conforme ilustra a Tabela 2. Assim as categorias encontradas são:

- Pilar econômico: Um pilar de uma empresa é o lucro, representando os ganhos por ação, como parte da contabilidade padrão. Para calcular o pilar convencional de uma empresa, os contadores levantam, registram e analisam uma grande gama de dados numéricos. Essa abordagem é vista como um modelo para a contabilidade ambiental e social, mas o desafio pode ser ainda maior nessas novas áreas da contabilidade empresarial. Então como uma empresa sustentável calcularia se suas operações são economicamente sustentáveis? Obviamente o primeiro passo seria entender o significado de capital econômico. Em seu termo mais simples, seu capital é o valor do seu ativo menos as suas obrigações. 
Marina Silva Paravidino de Abreu

Estácio Universidade Estácio de Sá, Campos dos Goytacazes, RJ, Brasil

marina.paravidino@live.com

ARTIGO

De acordo com Elkington (2012, p.112), "na teoria econômica tradicional, o capital como fator de produção pode ser encontrado de duas formas principais: capital físico (incluindo maquinário e fábrica e capital financeiro.”

Tabela 2. Classificação dos artigos por perspectiva de sustentabilidade em ordem de relevância na base de dados SciELO.

\begin{tabular}{|c|c|c|}
\hline Perspectiva & № de Referências & Referências \\
\hline Ambiental & 16 & $\begin{array}{l}\text { Jugend et al. (2017), Martens et al. (2016), Morioka et al (2015), } \\
\text { Almeida et al (2016), Teixeira et al (2013), Zamberlan et al. (2014), } \\
\text { Camargo et al. (2015), Fidalga et al. (2014), Brito et al. (2019), } \\
\text { Rudolpho et al. (2018), Fonseca et al. (2009), Calia et al. (2006), } \\
\text { Macedo et al. (2013), Cardona et al. (2010), Oliveira et al. (2015), } \\
\text { Colhaço et al. (2015). }\end{array}$ \\
\hline Econômica & 42 & $\begin{array}{l}\text { Zaneti et al. (2009), Tundisi et al (2008), Magalhães et al. (2014), } \\
\text { Zamcopé et al (2012), Santana et al. (2011), Dowbor et al. (2007), } \\
\text { França et al. (2012), Andreazzi et al. (2017), Mejía Soto et al. (2016), } \\
\text { Coelho et al. (2013), Vignochi et al. (2014), Agustini et al. (2015), } \\
\text { Mata-Lima et al. (2013), Rosa et al. (2017), Graça et al. (2019), } \\
\text { Santos et al. (2017), Hoganson et al. (2004), Hayran et al. (2019), } \\
\text { Mamede Andrade et al. (2013), Melo et al. (2019), Rocha et al. } \\
\text { (2012), SIlva et al. (2012), Rodrigues et al. (2003), Rueda-Galvis et al. } \\
\text { (2017), da Silva et al. (2009), Urrego Estrada et al. (2018), Pinto et al. } \\
\text { (2013), Schwarz et al. (2009), Oliveira et al. (2013), Schettino et al. } \\
\text { (2019), Teixeira et al. (2012), Assis et al. (2012), Espina Prieto et al. } \\
\text { (2007), Gutierrez Ossa et al. (2013), Mendonça et al. (2016), Noda et } \\
\text { al. (2012), Ramos et al. (2011), Gallina et al. (2012), Mendonça et al. } \\
\text { (2016), Palma et al. (2014), Torrens et al. (2014), Fernandes et al. } \\
\text { (2013). }\end{array}$ \\
\hline Social & 222 & Base de dados da plataforma SciELO (2020). \\
\hline $\begin{array}{l}\text { Tripple } \\
\text { bottom } \\
\text { line }\end{array}$ & 90 & Base de dados da plataforma SciELO (2020). \\
\hline
\end{tabular}

- Pilar ambiental: Provavelmente a agenda social tenha uma história mais longa para as empresas do que a agenda ambiental. Pense na escravidão, no trabalho infantil e nas más condições de trabalho. Mas depois de uma série de interesses sobre a questão social e auditoria 
na década de 1970, a agenda ambiental está propensa a atrair maior atenção. O resultado, paradoxalmente, é que no momento muitos executivos se sentem mais sendo desafiados nas questões ambientais do que nas questões sociais. Esse fato causa impacto no mercado a medida que a agenda da sustentabilidade é definida pelos executivos.

- Pilar social: Alguns envolvidos na comunidade do desenvolvimento sustentável insistem no fato de que a sustentabilidade não tem relação alguma com as questões sociais, éticas ou culturais. Então como uma empresa supostamente sustentável pensaria no capital social? Em parte, ela considera o capital humano, na forma de saúde, habilidades e educação, mas também deve abranger medidas mais amplas de saúde da sociedade e do potencial de criação de riqueza.

Uma consideração importante no trabalho que a SustainAbility fez recentemente é que o desenvolvimento sustentável é mais provável e será lançado a um menor custo para as economias em que existirem nas sociedades altos níveis de confiança e outras formas de capital social. Isso depende dos níveis e da igualdade de investimento em capital humano.

- Triple bottom line: Nessa visão, os artigos tratam da sustentabilidade sob a óptica da integração dos três pilares da sustentabilidade.

Conforme ilustrado na Figura 4, verifica-se que a participação de artigos sobre o pilar ambiental e social é semelhante. Por um lado, os artigos com ênfase ambiental estão mais ligados ao setor de construção civil, tratando do desenvolvimento sustentável em seus projetos como forma de agregar valor a seus produtos perante o cliente. Por outro lado, o pilar social dá mais atenção à necessidade da participação de diversos interessados no projeto, com o objetivo de aumentar as chances de sucesso, melhorar o desempenho etc.

\section{Figura 4. Distribuição dos artigos da amostra por pilar de sustentabilidade.}

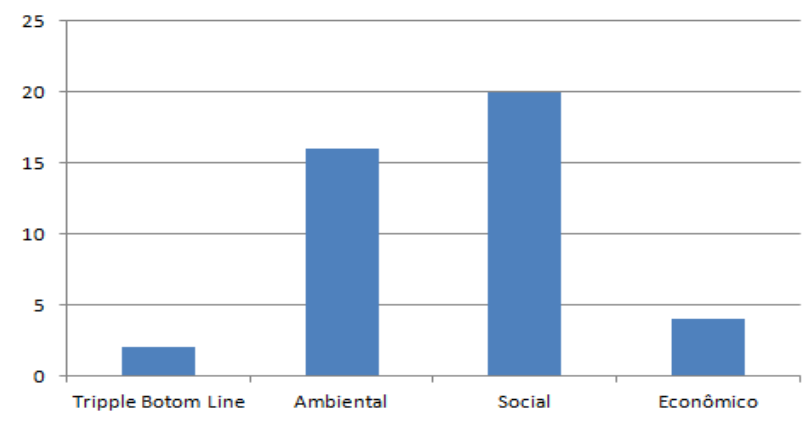

Fonte: Elaboração própria (2020). 
Vale também ressaltar que um dos temas tratados pelos artigos que enfatizam o pilar social está relacionado à participação de diversos indivíduos em um determinado projeto implantado. Isso pode ser verificado em diversos contextos, tanto na área da saúde, quanto em um ambiente de gestão empresarial. Assim, pode-se concluir que projetos e processos potencialmente se enriquecem com a participação de diversos pontos de vista, independente do contexto estudado.

\section{Análise dos artigos}

Tomando como princípio a amostra de artigos retirada da base de dados da SciELO, dois artigos selecionados apresentaram os seguintes termos: "sustentabilidade", "gestão", "ambiental" e "construção" no resumo ou como palavra-chave. A escolha dos artigos foi feita por ondem de citação. Marques et al. (2018), em seu artigo "Políticas públicas em prol da sustentabilidade na construção civil em municípios brasileiros", por exemplo, propõe a identificação dos aspectos inerentes às políticas públicas adotadas em municípios brasileiros que estimulam a implementação de práticas sustentáveis na construção civil, vinculadas a programas municipais, incentivos ou legislações. A metodologia da pesquisa foi pautada em quatro etapas conforme a figura 5 .

Figura 5. Etapas da metodologia.

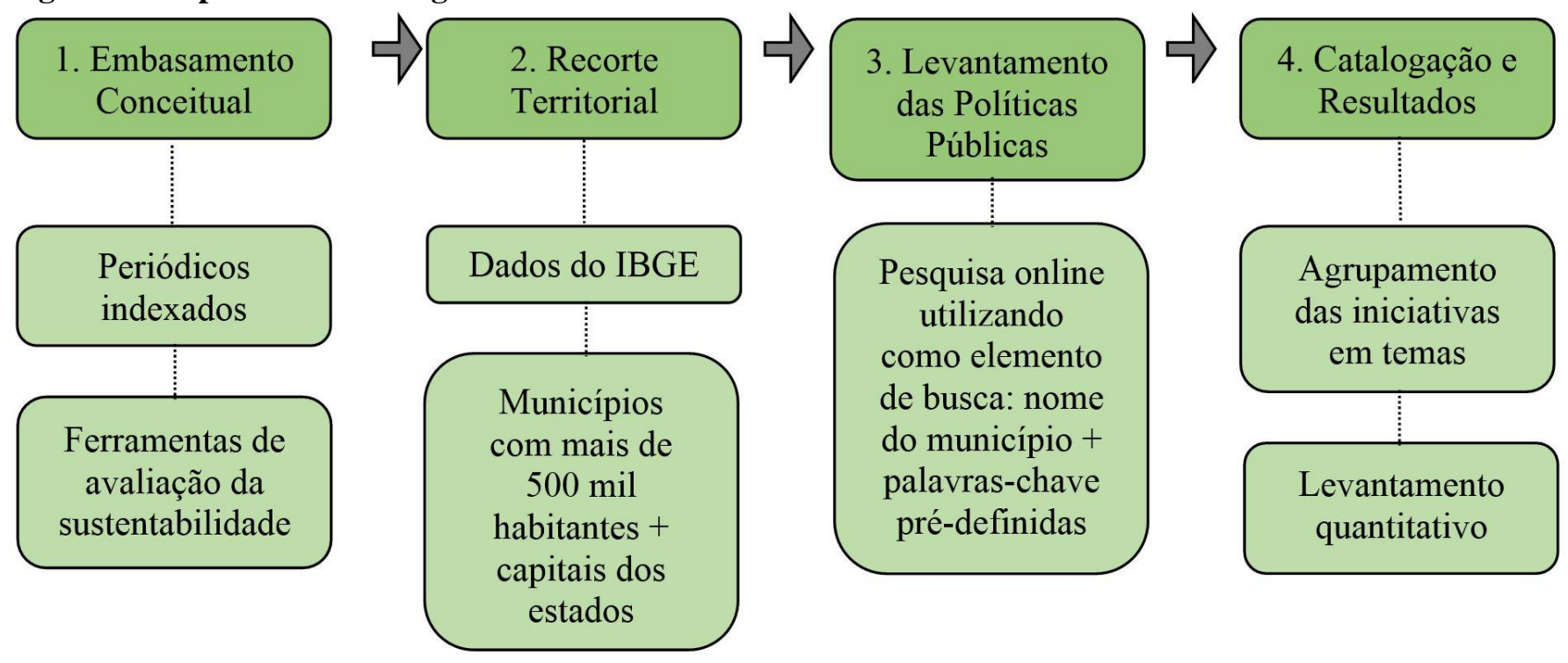

Fonte: Marques et al. (2018). 
Os resultados obtidos consideram, inicialmente, a identificação dos municípios e as respectivas políticas adotadas em prol da sustentabilidade. Estas foram subdivididas em categorias, posteriormente catalogadas de acordo com os temas abordados e mais uma vez separadas em dois grandes grupos de influência. Em ambos foi feito um diagnóstico do tema de destaque por região. Como estudo complementar, foi avaliada a relação entre os resultados da pesquisa - que sugerem uma relação de equivalência maior ou menor da qualidade de vida dos usuários - e o IDHM.

O Brasil possui 5.570 municípios ( IBGE, 2016 ). Considerando os que possuem acima de 500 mil habitantes e todas as capitais dos Estados, o levantamento resultou em uma amostragem de 47 municípios, além de identificar 168 iniciativas vinculadas às políticas públicas que abordam os aspectos inerentes à sustentabilidade em edificações e seu entorno, os quais incluem programas municipais, incentivos e leis, sendo os percentuais expostos na Figura 6.

Figura 6. Percentuais de programas municipais realizados nas regiões.

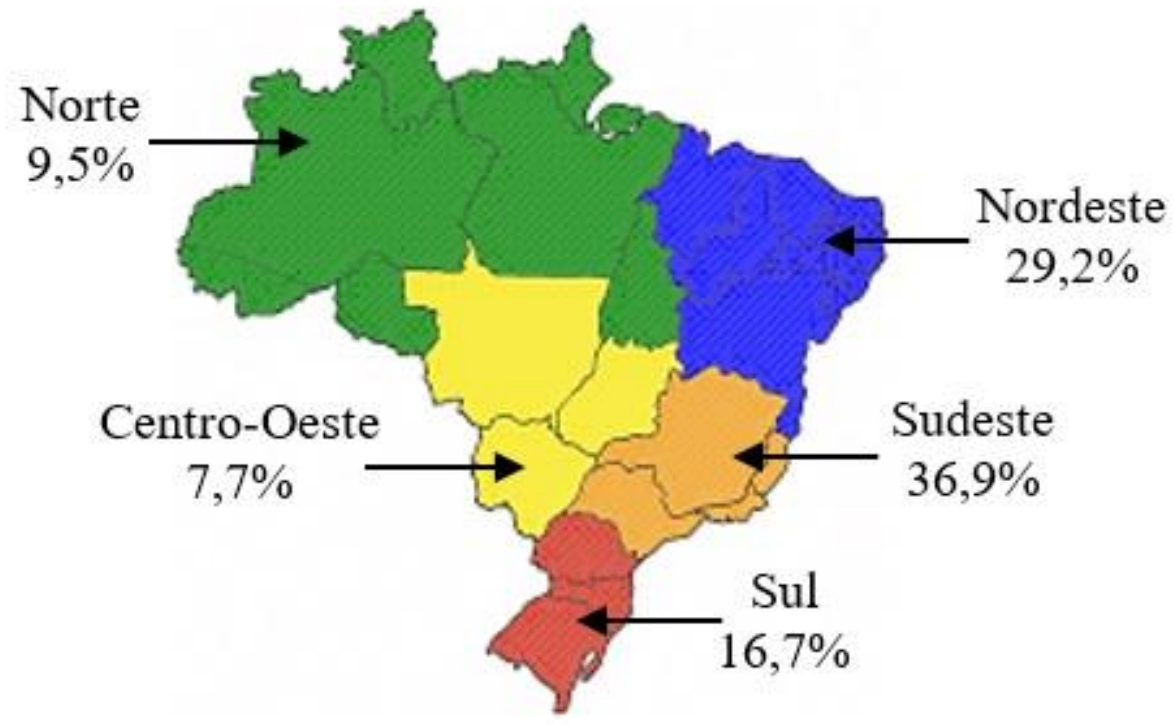

Fonte: Marques et al. (2018).

A região Sudeste teve a maior representatividade na amostragem. Nela estão contidos os Estados de maior densidade demográfica do país - São Paulo e Rio de Janeiro, com 166,23 e 365,23 hab/km2, respectivamente - e também concentra os maiores polos de desenvolvimento do Brasil. Na Tabela 3, estão representados os quantitativos de iniciativas públicas identificadas por região brasileira. 
Tabela 3 - Quantidade de iniciativas públicas identificadas em prol da sustentabilidade nas edificações por regiões brasileiras, com destaque para os resultados da região Sul.

\begin{tabular}{|c|c|c|c|c|c|c|}
\hline Regiäo & $\begin{array}{c}\text { Municipios com mais de } 500 \text { mil hab. e } \\
\text { capitais de Estado }\end{array}$ & $\begin{array}{c}\mathrm{N}^{\circ} \mathrm{de} \\
\text { habitantes1 }\end{array}$ & $\begin{array}{l}\mathrm{N}^{\circ} \text { de } \\
\text { municípios } \\
\text { por regiäo }\end{array}$ & $\begin{array}{l}\mathrm{N}^{\circ} \text { de } \\
\text { iniciativas } \\
\text { por regiăo }\end{array}$ & $\begin{array}{c}\text { Média de } \\
\text { iniciativas } \\
\text { por } \\
\text { municipio }\end{array}$ & $\begin{array}{c}\text { Relação de } \\
\text { iniciativas a } \\
\text { cada } 100 \text { mil } \\
\text { hab. }\end{array}$ \\
\hline $\mathrm{N}$ & $\begin{array}{l}\text { Porto Velho (RO), Rio Branco (AC), Manaus (AM), } \\
\text { Boa Vista (RR), Ananindeua (PA), Belém (PA), } \\
\text { Macapá (AP) e Palmas (TO). }\end{array}$ & 6.011 .313 & 8 & 16 & 2,00 & 2,70 \\
\hline NE & $\begin{array}{l}\text { São Luís (MA), Teresina (PI), Fortaleza (CE), Natal } \\
\text { (RN), João Pessoa (PB), Jaboatão dos Guararapes } \\
\text { (PE), Recife (PE), Maceió (AL), Aracaju (SE), Feira de } \\
\text { Santana (BA) e Salvador (BA). }\end{array}$ & 13.760 .132 & 11 & 49 & 4,45 & 3,60 \\
\hline SE & $\begin{array}{l}\text { Belo Horizonte (MG), Contagem (MG), Juiz de Fora } \\
\text { (MG), Uberlândia (MG), Vitória (ES), Duque de Caxias } \\
\text { (RJ), Nova lguaçu (RJ), Rio de Janeiro (RJ), São } \\
\text { Gonçalo (RJ), Campinas (SP), Guarulhos (SP), } \\
\text { Osasco (SP), Ribeirão Preto (SP), Santo André (SP), } \\
\text { São Bernardo do Campo (SP), São José dos Campos } \\
\text { (SP), São Paulo (SP) e Sorocaba (SP). }\end{array}$ & 32.786 .244 & 18 & 62 & 3,44 & 1,90 \\
\hline $\mathrm{s}$ & $\begin{array}{l}\text { Curitiba (PR), Londrina (PR), Florianópolis (SC), } \\
\text { Joinville (SC) e Porto Alegre (RS). }\end{array}$ & 4.975 .852 & 5 & 28 & 5,60 & 5,60 \\
\hline $\mathrm{CO}$ & $\begin{array}{l}\text { Campo Grande (MS), Cuiabá (MT), Aparecida de } \\
\text { Goiânia (GO), Goiânia (GO) e Brasilia (DF). }\end{array}$ & 6.407 .339 & 5 & 13 & 2,60 & 2,00 \\
\hline Total & & & 47 & 168 & - & - \\
\hline
\end{tabular}

Nota: Somatório dos habitantes das cidades catalogadas no recorte por região.

Fonte: Marques et al. (2018).

Nota-se que, apesar de a região Sudeste possuir a maior quantidade de municípios, a região Sul apresenta a maior média. Isso pode ser um indicativo de que, nesta última região, há uma maior preocupação com o discurso da sustentabilidade. Por outro lado, a região Norte apresenta a pior média. Quando é feita uma análise complementar para verificar a média de iniciativas por habitantes, a região Sul mantém seu destaque entre as demais. Entretanto, a média por habitante não se mostra proporcional à média por município, com a pior média por habitante sendo a da região Sudeste.

Outro artigo para análise, foi sobre "Consumo de água e energia em canteiros de obra: um estudo de caso do diagnóstico a ações visando à sustentabilidade”, por exemplo, Marque et al. (2017), apresenta que no contexto do desenvolvimento sustentável, a indústria da construção civil enfrenta desafios, entre eles a busca por maiores níveis de qualidade e eficiência em seus processos produtivos e no consumo dos recursos naturais. O objetivo é apresentar uma análise do consumo de energia e de água durante a fase construtiva das edificações, demonstrando medidas que podem ser adotadas no processo de produção a fim de reduzir o consumo dos referidos insumos e melhorar o desempenho dos processos em uma construtora. A pesquisa foi realizada em seis obras de uma construtora na cidade de Passo Fundo, RS, mediante o monitoramento dos consumos mensais ao longo de 5 anos. Como resultados são propostas ações econômicas, tecnológicas e sociais para melhorias nesses indicadores. Os resultados demonstram que são necessários o monitoramento 
e a gestão contínua do consumo de água e energia dentro dos canteiros de obra. Entre as ações sugeridas destaca-se o comprometimento da direção da empresa com a eficiência no uso dos recursos na obra.

O estudo analisa uma construtora localizada na cidade de Passo Fundo atuante desde 1975 na construção civil, tendo executado mais de 60 prédios comerciais e residenciais, superando $250.000 \mathrm{~m} 2$ de área construída. A empresa é certificada pelo Programa Brasileiro de Qualidade e Produtividade no Habitat (PBQP-H), nível A, e pela norma ISO 9001, com um sistema de gestão da qualidade implementado há mais de dez anos.

Para o estudo foram selecionadas seis obras (Figura 7) executadas no período compreendido entre fevereiro de 2012 e outubro de 2016, únicas obras com os dados dos indicadores completos, com medições do início ao fim da execução.

Figura 7. Obras analisadas.
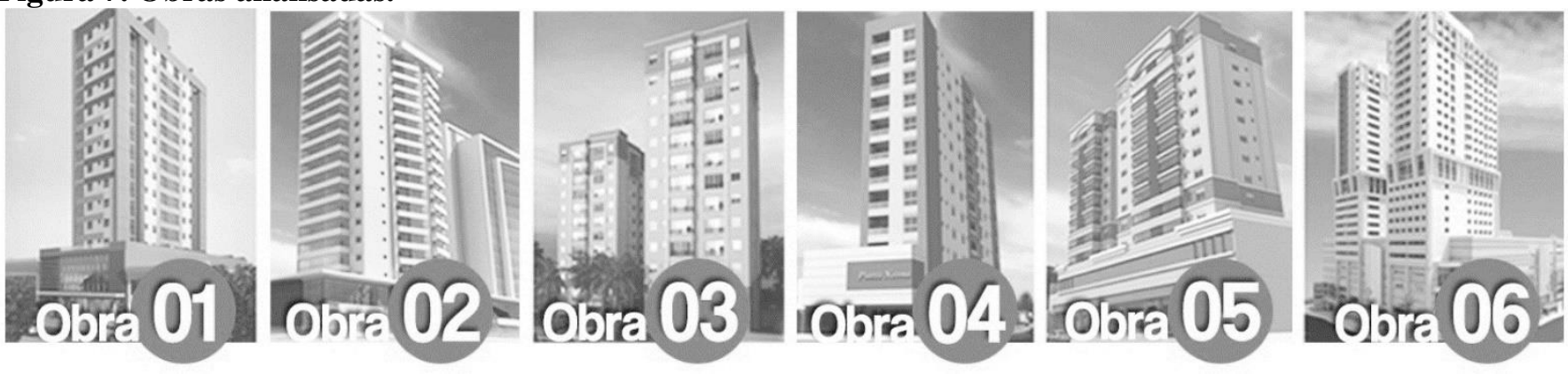

Fonte: Marques et al. (2017).

Pelo fato de possuírem sistema de gestão da qualidade, as obras executadas pela empresa contam com uma série de controles em seus processos e serviços; por isso seus canteiros apresentaram certa regularidade na maneira com que são organizados, com padronização. Como as certificações que a empresa possui dizem respeito à gestão da qualidade, trazem como principal foco a qualidade do produto e a satisfação de seus clientes externos. Ao se acompanharem as obras da empresa para a coleta de dados, observou-se que as questões ambientais são relegadas a segundo plano, e, por mais que algumas das ações de controle já sejam realizadas pela empresa, estas não são eficazes para as questões ambientais, ficando restritas apenas ao atendimento de requisitos exigidos pelas normas de qualidade (BRASIL, 2012; ABNT, 2001).

As principais características das obras avaliadas no estudo são apresentadas na Tabela 4. 
Marina Silva Paravidino de Abreu

Tabela 4 - Características das obras analisadas

\begin{tabular}{|c|c|c|c|c|c|c|c|c|c|c|c|}
\hline Obra & $\begin{array}{c}\text { Tipo de } \\
\text { obra }\end{array}$ & $\begin{array}{l}\text { Sist.Cons- } \\
\text { trutivo }\end{array}$ & For-mas & $\begin{array}{l}\text { Esco- } \\
\text { ramen- } \\
\text { tos }\end{array}$ & $\mathbf{N}^{\circ}$ Pav. & $\mathrm{N}^{\circ}$ Und. & $\begin{array}{c}\text { Tipo(1d, } \\
\text { 2d,kit, } \\
\text { etc.) }\end{array}$ & $\begin{array}{l}\text { Área laje } \\
\text { tipo }\left(\mathrm{m}^{2}\right)\end{array}$ & $\begin{array}{c}\text { Perí- } \\
\text { metro } \\
\text { tipo (m) }\end{array}$ & $\begin{array}{c}\text { Área real } \\
\text { global }\left(\mathrm{m}^{2}\right)\end{array}$ & $\begin{array}{l}\text { Indice } \\
\text { compa- } \\
\text { cidade } \\
\text { (IC) }\end{array}$ \\
\hline 01 & $R$ & $C A$ & $\mathrm{CB}$ & $\mathrm{ME}$ & 15 & 84 & $7 \times K I T$ & 283 & 91 & 6.224 & 0,66 \\
\hline \multirow{2}{*}{02} & R & \multirow{2}{*}{$C A$} & MA & MA & 20 & 102 & $\begin{array}{l}2 \times 1 \mathrm{D} \\
4 \times K I T\end{array}$ & 275 & 95 & \multirow{2}{*}{15.969} & 0,76 \\
\hline & $\mathrm{C}$ & & $\mathrm{CB}$ & $\mathrm{ME}$ & 16 & 104 & \begin{tabular}{|l|} 
8 Salas \\
\end{tabular} & 420 & 95 & & 0,84 \\
\hline \multirow{2}{*}{03} & $\mathrm{R}$ & \multirow{2}{*}{$C A$} & \multirow{2}{*}{ MA } & \multirow{2}{*}{$\mathrm{ME}$} & 14 & 52 & $3 \times 2 \mathrm{D}, 1 \times 3 \mathrm{D}$ & 315 & 75 & 13.705 & 0,80 \\
\hline & $\mathrm{R}$ & & & & 12 & 44 & $3 \times 2 \mathrm{D}, 1 \times 3 \mathrm{D}$ & 315 & 75 & 8.190 & 0,80 \\
\hline 04 & $R$ & $C A$ & MA & MA/ME & 12 & 40 & $3 \times 2 \mathrm{D}, 1 \times 3 \mathrm{D}$ & 380 & 105 & 5.568 & 0,63 \\
\hline \multirow{2}{*}{05} & $\mathrm{R}$ & \multirow{2}{*}{$C A$} & \multirow{2}{*}{ MA } & \multirow{2}{*}{ MA } & 12 & 27 & \begin{tabular}{|c|}
$3 \times K I T$ \\
\end{tabular} & 120 & 50 & \multirow{2}{*}{5.046} & 0,78 \\
\hline & $R$ & & & & 13 & 30 & $1 \times 1 D, 2 \times 2 D$ & 200 & 65 & & 0,77 \\
\hline 08 & $\mathrm{C}$ & $C A$ & MA & MA & 21 & 169 & \begin{tabular}{|c|} 
9 Salas \\
\end{tabular} & 450 & 90 & 48870,8 & 0,84 \\
\hline
\end{tabular}

Fonte: Marques et al. (2017).

Nota: Legenda: Tipo de obra: $\mathrm{R}=$ Residencial; $\mathrm{C}=$ Comercial; Sistema construtivo: $\mathrm{CA}=\mathrm{Concreto}$ armado; Formas: $\mathrm{CB}=$ Cubetas; MA = Madeira; Escoramentos: ME = Metálico; MA = Madeira; Revestimentos: $\mathrm{A}=$ Argamassado; $\mathrm{T}=\mathrm{Textura} ; \mathrm{PA}=$ Pastilha; PE = Pele de vidro; e Tipo: 1D = 1 Dormitório; 2D = 2 Dormitórios; 3D = 3 Dormitórios; KIT = Quitinete.Fonte: Marques et al. (2018).

O cálculo do indicador para as obras do estudo permitiu identificar que os empreendimentos que apresentaram o maior índice de compacidade são do tipo comercial com valores de 0,84 nas obras 2 e 6 , enquanto para as demais obras (residenciais) os índices apresentaram valores menores. Essas afirmativas propiciam as análises subsequentes em conjunto com indicadores de consumo.

A análise dos valores dos indicadores relativos ao consumo de água e energia é apresentada na Tabela 5 para as seis obras analisadas.

Tabela 5 - Indicador consumo de energia $\left(\mathrm{kWh} / \mathrm{m}^{2}\right)$ e água $\left(\mathrm{m}^{3} / \mathrm{m}^{2}\right)$

\begin{tabular}{|c|c|c|c|c|c|c|}
\hline Obra & $\begin{array}{c}\text { Área } \\
\text { construída }\left(\mathrm{m}^{2}\right)\end{array}$ & $\begin{array}{c}\text { Indice de } \\
\text { compaci-dade } \\
\text { (IC) }\end{array}$ & $\begin{array}{l}\text { Consumo total } \\
\text { de energia } \\
\text { (kWh) }\end{array}$ & Indicador $\left(\mathrm{kWh} / \mathrm{m}^{2}\right)$ & $\begin{array}{l}\text { Consumo total } \\
\text { de água }\left(\mathrm{m}^{3}\right)\end{array}$ & Indicador $\left(\mathrm{m}^{3} / \mathrm{m}^{2}\right)$ \\
\hline 1 & $6.223,66$ & 0,68 & $60.907,00$ & 9,79 & $1.721,22$ & 0.28 \\
\hline 2 & $15.969,04$ & $0,76 / 0,84$ & $4.302,51$ & 0,27 & 183,10 & 0,01 \\
\hline 3 & 13.704 .93 & $0,80 / 0,80$ & $97.500,00$ & 7,11 & $2.363,68$ & 0,17 \\
\hline 4 & $5.567,81$ & 0,66 & $55.266,00$ & 9,93 & $1.025,00$ & 0,18 \\
\hline 5 & $5.046,30$ & $0,78 / 0,77$ & $11.382,36$ & 2,26 & 655,20 & 0,13 \\
\hline 6 & $48.870,81$ & 0,84 & $39.679,22$ & 0,81 & 840,52 & 0,02 \\
\hline
\end{tabular}

Fonte: Marques et al. (2017).

Os valores obtidos revelam uma variação para o consumo de água entre $0,02 \mathrm{~m} 3 / \mathrm{m} 2$ e 0,28 m3/m2 e indicam patamares de consumo inferiores aos encontrados em pesquisas já citadas na literatura (MCCORNACK et al., 2007; BARDHAN, 2011; SANTOS; SILVA; CERQUEIRA, 2015).

No indicador consumo de energia os valores encontraram-se entre 0,27 kWh/m2 e 9,93 kWh/m2 para as seis obras monitoradas. 
Marina Silva Paravidino de Abreu

Estácio Universidade Estácio de Sá, Campos dos Goytacazes, RJ, Brasil

marina.paravidino@live.com

ARTIGO

Os gráficos apresentados na figura 8, permitem uma visualização em termos comparativos dos indicadores (valores médios) para as seis obras.

Figura 8. Gráficos indicadores de consumo de energia e água por área construída.
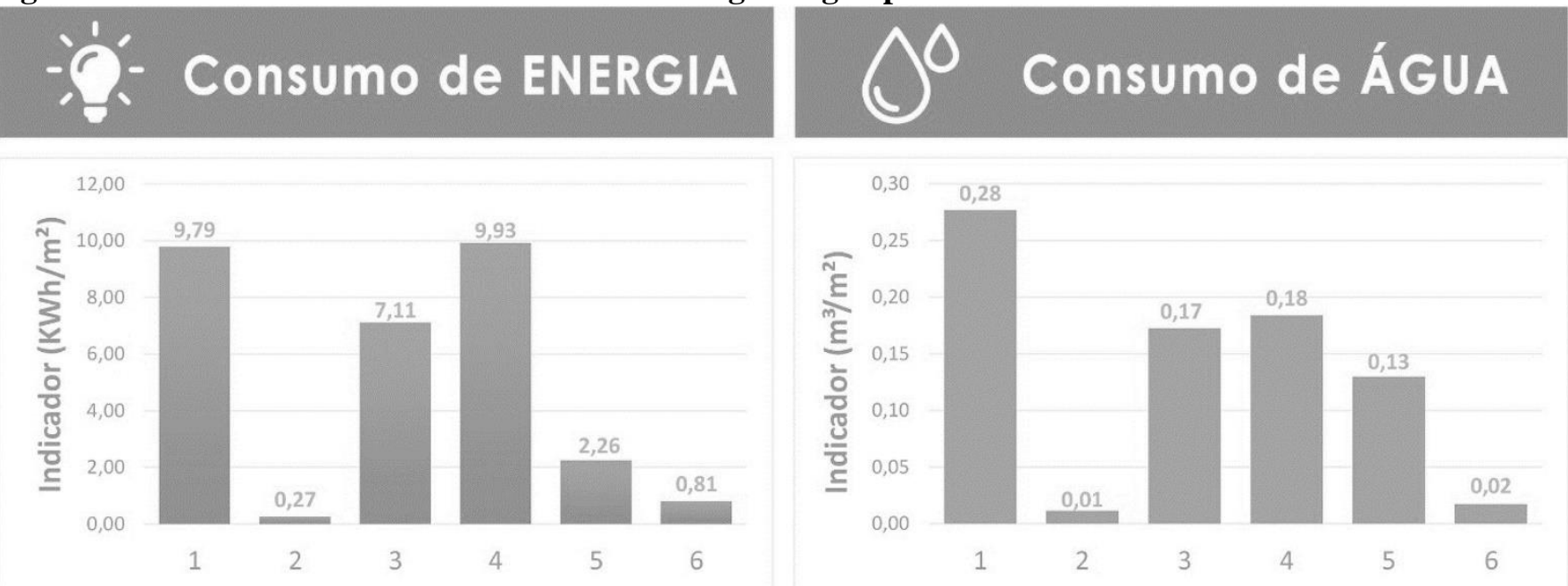

Obras

Obras

Fonte: Marques et al. (2017).

Os resultados obtidos para os indicadores de consumo de energia em $\mathrm{kWh}$ por área construída e consumo de água em volume por área construída para as seis obras analisadas (Tabela 5 e Figura 8) levam a algumas constatações:

a) as duas obras com maior área construída (obras 2 e 6) apresentaram o menor consumo de energia e de água;

b) as duas obras com menor consumo de energia e água (obras 2 e 6) são do tipo comercial; e

c) as duas obras com maior IC (obras 2 e 6) apresentaram o menor consumo de energia e água, e vice-versa, ou seja, as duas obras com menor índice de compacidade apresentaram o maior consumo.

Com a redução na quantidade de execução dos serviços citados, tem-se menor consumo de água e energia, que estariam incorporados nos processos construtivos, bem como a redução na geração de resíduos e a consequente necessidade de limpeza do canteiro de obra. Considerando uma análise do canteiro de obra, com a adoção das divisórias em gesso acartonado ocorre o mesmo, uma vez que esse serviço requer menos consumo de água e energia em sua instalação quando comparado a uma parede convencional, o que não pode 
ser verificado quando se analisa o ciclo de vida completo da produção de uma parede de gesso acartonado, incluindo todos os seus insumos e matérias-primas requeridos.

Como ações propostas, foram feitas vistorias nas obras que não só forneceram subsídios para o conhecimento das características técnicas e construtivas, como também propiciaram o levantamento dos principais problemas relacionados ao consumo de água e energia dentro dos canteiros de obras. A partir destes problemas, foram definidas ações que podem ser incorporadas pela empresa ou outras organizações que executam empreendimentos similares para a redução do consumo e desperdício de energia e água nos canteiros de obra. O Quadro 1 apresenta essas ações juntamente com seus efeitos e benefícios.

Quadro 1. Ações propostas para redução do consumo de energia e água

\begin{tabular}{|c|c|c|c|c|}
\hline \multirow{5}{*}{$\begin{array}{l}\text { AÇÕES } \\
\text { ECOONỔMICAS }\end{array}$} & PROBLEMAS & ACCOESS & EFEITOS & BENEFICIOS \\
\hline & $\begin{array}{l}\text { Etapas de projeto com problemas } \\
\text { de comunicação entre as partes } \\
\text { envolvidas. }\end{array}$ & $\begin{array}{l}\text { Promover reuniões periódicas } \\
\text { para a realização de tomadas de } \\
\text { decisão, integrando as equipes do } \\
\text { projeto arquitetônico com as } \\
\text { equipes dos projetos } \\
\text { complementares. }\end{array}$ & $\begin{array}{l}\text { Reduzir a relação área de } \\
\text { fachada-área construída, usar } \\
\text { sistemas construtivos } \\
\text { industrializados, reduzir } \\
\text { elementos que consomem } \\
\text { energia e água para sua } \\
\text { execução no canteiro de obra. }\end{array}$ & $\begin{array}{l}\text { Otimizar e reduzir desperdícios de } \\
\text { água, energia e materiais. }\end{array}$ \\
\hline & $\begin{array}{l}\text { Restrições por parte da direção } \\
\text { na liberação de verbas para a } \\
\text { realização de algumas ações de } \\
\text { melhorias no sistema de gestão. }\end{array}$ & $\begin{array}{l}\text { Incentivo financeiro por parte da } \\
\text { direção da empresa para a } \\
\text { realização de melhorias para o } \\
\text { funcionamento eficiente de todos } \\
\text { os sistemas, bem como } \\
\text { planejamento, controle e gestão } \\
\text { dos canteiros de obra. }\end{array}$ & $\begin{array}{l}\text { Assegurar os investimentos } \\
\text { necessários para manutenção do } \\
\text { gerenciamento das açóes de } \\
\text { controle de consumo de energia e } \\
\text { água nos canteiros de obra. }\end{array}$ & $\begin{array}{l}\text { Reduzir desperdícios de água, } \\
\text { energia e materiais, bem como a } \\
\text { geração de resíduos da construção } \\
\text { civil. }\end{array}$ \\
\hline & $\begin{array}{l}\text { Utilização de equipamentos sem } \\
\text { manutenção, levando ao uso } \\
\text { inadequado e consequente maior } \\
\text { consumo de energia devido à } \\
\text { sobrecarga de tarefas para o } \\
\text { profissional responsável pelas } \\
\text { manutenções preventivas. }\end{array}$ & $\begin{array}{l}\text { Disponibilização de mão de obra } \\
\text { exclusiva para realização de } \\
\text { adequadas e efetivas } \\
\text { manutenções preventivas e } \\
\text { corretivas dos equipamentos, } \\
\text { observando suas especificações } \\
\text { quando da necessidade de } \\
\text { substituição de } \\
\text { peças/componentes. }\end{array}$ & $\begin{array}{l}\text { Garantir que todos os } \\
\text { equipamentos sejam utilizados de } \\
\text { maneira adequada e de acordo } \\
\text { com as especificaçóes de uso do } \\
\text { fabricante, aumentando sua } \\
\text { eficiência e durabilidade, evitando } \\
\text { riscos de acidentes e reduzindo } \\
\text { consumo de energia. }\end{array}$ & $\begin{array}{l}\text { Reduzir o consumo de energia por } \\
\text { equipamentos avariados. }\end{array}$ \\
\hline & $\begin{array}{l}\text { Inexistência de inspeções acerca } \\
\text { das instalações provisórias e } \\
\text { tubulações das áreas de vivência } \\
\text { do canteiro de obras. }\end{array}$ & $\begin{array}{l}\text { Disponibilização de mão de obra } \\
\text { exclusiva para realização de } \\
\text { inspeções periódicas nas } \\
\text { instalações provisórias na busca } \\
\text { de possiveis vazamentos no } \\
\text { canteiro de obra. }\end{array}$ & $\begin{array}{l}\text { Garantir que não ocorram } \\
\text { vazamentos nos canteiros de obra } \\
\text { e, caso ocorram, que eles sejam } \\
\text { identificados rapidamente para } \\
\text { maior agilidade em sua resolução. }\end{array}$ & $\begin{array}{l}\text { Reduzir o consumo de água } \\
\text { decorrente a vazamentos. }\end{array}$ \\
\hline $\begin{array}{l}\text { AÇÕES } \\
\text { ECCONỔMICAS }\end{array}$ & $\begin{array}{l}\text { No momento da compra não é } \\
\text { levada em consideração a } \\
\text { eficiência dos equipamentos, } \\
\text { máquinas e eletrodomésticos para } \\
\text { as instalaçóes provisórias das } \\
\text { obras, sendo considerados } \\
\text { apenas os custos de sua } \\
\text { aquisição. }\end{array}$ & $\begin{array}{l}\text { Utilização de equipamentos e } \\
\text { máquinas certificados pelo } \\
\text { Programa Brasileiro de } \\
\text { Etiquetagem do Inmetro, possuir o } \\
\text { selo Procel ou Conpet nivel A, } \\
\text { considerando a especificidade a a } \\
\text { necessidade de cada item } \\
\text { (equipamentos utilizados na } \\
\text { execução do empreendimento, } \\
\text { como serras manuais, } \\
\text { rompedores, etc-; também, } \\
\text { eletrodomésticos utilizados no } \\
\text { refeitório, almoxarifado, vestiários, } \\
\text { etc.). }\end{array}$ & $\begin{array}{l}\text { Garantir que apenas sejam } \\
\text { adquiridos e utilizados } \\
\text { equipamentos com qualidade } \\
\text { comprovada e reconhecida, e } \\
\text { com certificação de eficiência } \\
\text { energética. }\end{array}$ & Reduzir o consumo de energia. \\
\hline
\end{tabular}


Marina Silva Paravidino de Abreu

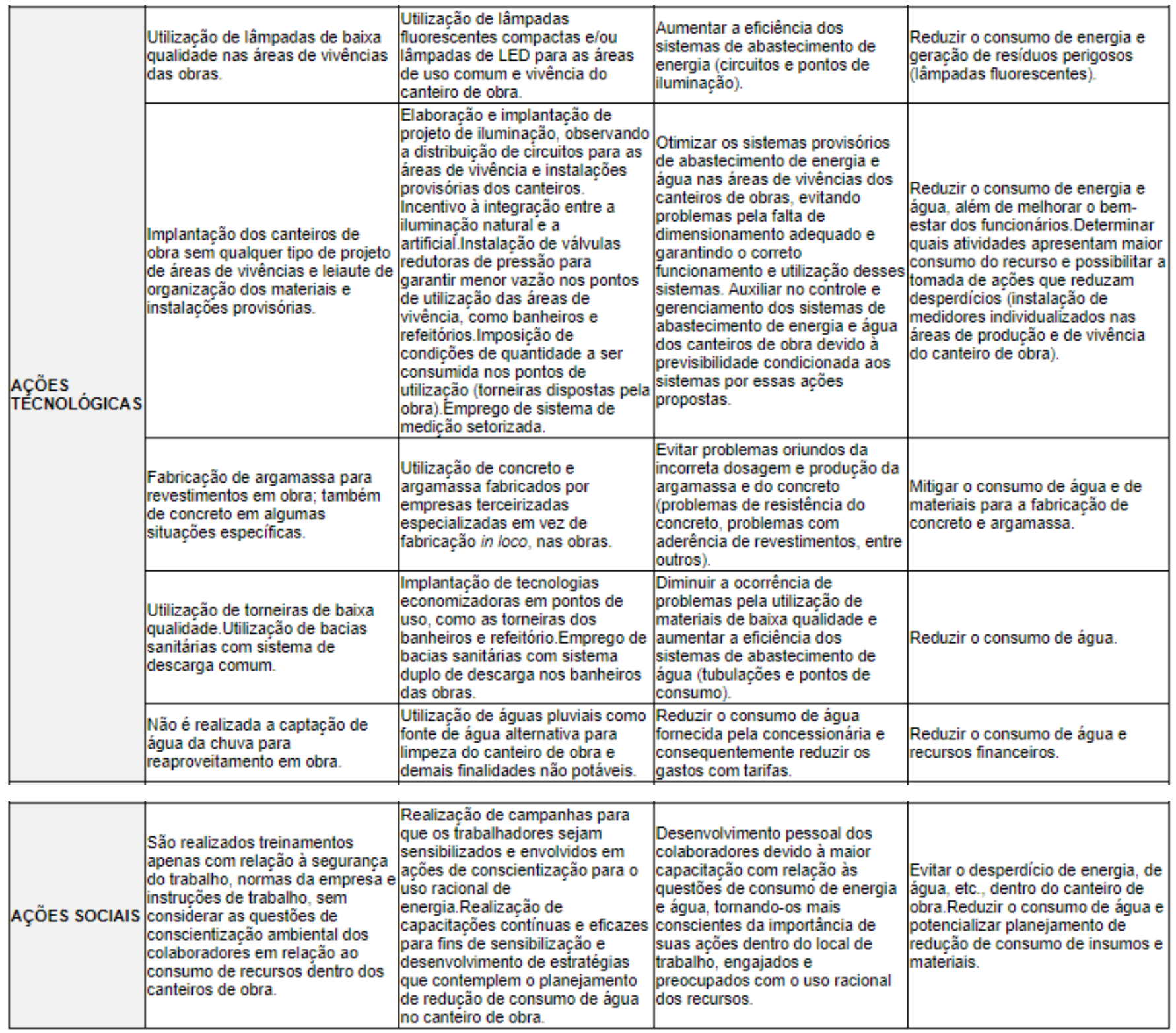

Fonte: Marques et al. (2017).

A avaliação dos consumos de água e energia em canteiros de obra possibilita um tratamento do uso desses recursos com maior eficiência, de forma que a empresa, além de monitorar seu desempenho, possa identificar possíveis falhas nos sistemas e principalmente possibilidades de otimização deles.

Todas as ações propostas foram baseadas com vistas a reduzir o consumo e desperdício de energia e água nos canteiros de obra, podem ser incorporadas por outras organizações que executam empreendimentos 
Marina Silva Paravidino de Abreu

com características semelhantes: habitacionais e comerciais com estrutura convencional em concreto armado.

Um aspecto importante é o comprometimento da empresa com a eficiência no uso dos recursos na obra. Este é o ponto inicial e talvez crucial para a implementação de ações de melhoria, uma vez que estas envolvem investimentos, desde um projeto racional, uso de tecnologias e materiais economizadores, alocação da mão de obra para manutenção e inspeção, e desenvolvimento dos colaboradores.

Inicialmente, vale ressaltar que as referências analisadas reforçam a evidência de que o uso do termo sustentabilidade já está bastante presente nas empresas e que já existe uma preocupação com a questão ambiental, social e econômica para fins de se ter um futuro promissor.

\section{Considerações finais}

O trabalho teve como objetivo proporcionar uma visão geral sobre os principais artigos que tratam tanto de gestão de projetos quanto de sustentabilidade. Isso porque, uma vez que os projetos possuem consequências que vão além de seu término, o estudo de processos ligados à gestão de projetos pode ser uma ferramenta relevante para fazer com que as organizações utilizem abordagem sustentável. Assim, verificar as publicações existentes no assunto contribui fortemente na identificação de vazios de conhecimento a serem complementados no futuro.

Os artigos mais relevantes em termos de citações tratam da sustentabilidade sob uma visão mais especifica de um determinado pilar (social, econômico ou ambiental) e não de como a gestão de projetos se relaciona com o triple bottom line.

Ainda, algumas evidências apontam para um esforço maior para estudar o desenvolvimento sustentável em projetos na área da construção civil. Isso porque as revistas de maior concentração de publicações dentro da amostra estudada são dedicadas a essa área.

Quando se fala em sustentabilidade tratada juntamente à gestão de projetos, diversos stakeholders devem ser envolvidos, tais como a comunidade e a liderança, evidenciando a importância da participação e parceria entre os envolvidos. Essa temática foi identificada principalmente analisando-se os agrupamentos da rede de palavras-chave. 
Marina Silva Paravidino de Abreu

Assim, conforme mostrado neste trabalho, os artigos que tratam tanto de gestão de projetos quanto de sustentabilidade estão sendo publicados há mais de duas décadas, sendo que a partir de 2005 verifica-se um incremento no número de artigos.

Este estudo apresenta limitações resultantes das escolhas metodológicas. A primeira relacionada à escolha da amostra inicial na base SciELO, que tem um número limitado de títulos, o que pode ter deixado trabalhos relevantes fora da amostra estudada. Segundo a análise de citação gera um viés temporal dado que os trabalhos e referências mais citados tendem a ser os mais antigos.

\section{Referências}

ALMEIDA, Fernanda. Experiências empresariais em sustentabilidade: avanços, dificuldades e motivações de gestores e empresas. Rio de Janeiro, RJ: Elsevier, 2009.

ELKINGTON, John. Canibais com garfo e faca, Sustentabilidade. São Paulo: M.Books do Brasil Editora Ltda, 2012. P. 107131.

FREITAS, Marcílio de; FREITAS, Marilene Corrêa da Silva. Será o desenvolvimento sustentável o último estágio de opressão do capitalismo? A sustentabilidade como paradigma: Cultura, ciência e cidadania. Petrópolis, RJ: Vozes, 2016.

KUNSCH, Margarida Maria Krohling; OLIVEIRA, Ivone de Lourdes. Série pensamento e prática: a comunicação na gestão da sustentabilidade das organizações. São Caetano do Sul, SP: Difusão Editora, 2009.

LAZZARI, Márcia Cristina. Sustentabilidade sob a ecopolítica: considerações acerca das questões ambientais no amazonas. Manaus: UEA Edições, 2018.

LEFF, Enrique. Saber ambiental: Sustentabilidade, Racionalidade, Complexidade, Poder. Petrópolis, RJ: Vozes, 2012.

LOURES, Rodrigo C. da Rocha. Sustentabilidade XXI. Educar e inovar sob uma nova consciência. São Paulo, SP: Editora Gente, 2009.

MALVEZZI, Mariana. Sustentabilidade e emancipação: a gestão de pessoas na atualidade. São Paulo, SP: Editora Senac São Paulo, 2013.

MARQUES, Cristian Teixeira; GOMES, Bárbara Maria Fritzen; BRANDLI, Luciana Londero. Consumo de água e energia em canteiros de obra: um estudo de caso do diagnóstico a ações visando à sustentabilidade. Ambient. constr., Porto Alegre, v. 17, n. 4, p. 79-90, Dec. 2017.

MARQUES, Suelem Bertollo; BISSOLI-DALVI, Márcia; ALVAREZ, Cristina Engel de. Políticas públicas em prol da sustentabilidade na construção civil em municípios brasileiros. urbe, Rev. Bras. Gest. Urbana, Curitiba, v. 10, supl. 1, p. 186-196, nov. 2018.

MORIOKA, Sandra Naomi; CARVALHO, Marly Monteiro de. Sustentabilidade e gestão de projetos: um estudo bibliométrico. Universidade de São Paulo, São Paulo, SP, Brasil, Production, 26(3), 656-674, jul.set.2016.

NETO, João Amato. Sustentabilidade e Produção: teoria e prática para uma gestão sustentável. São Paulo, SP: Atlas, 2011. 
Marina Silva Paravidino de Abreu

marina.paravidino@live.com

ARTIGO

SÁ, Sônia Maria Neves Bittencourt de. Esporte de natureza, políticas públicas e sustentabilidade: reflexões para gestão Pública das Cidades. Curitiba: Editora Appris, 2015.

\section{Agradecimentos}

Agradeço aos avaliadores do trabalho da Universidade Estácio de Sá. Agradeço também a Capes que disponibilizou o acesso livre ao banco de dados da plataforma SciELO. 